Available online on 15.03.2018 at http://jddtonline.info
Journal of Drug Delivery and Therapeutics
Open Access to Pharmaceutical and Medical Research
$\begin{gathered}\text { (c) 2011-18, publisher and licensee JDDT, This is an Open Access article which permits unrestricted non- } \\ \text { commercial use, provided the original work is properly cited }\end{gathered}$

Open $\odot$ Access

Research Article

\title{
EVALUATION OF ANTIDIABETIC ACTIVITY OF FRUITS OF WITHAHNIA COAGULANS IN STREPTOZOCIN INDUCED DIABETIC RATS
}

\author{
Upadhayay Ashutosh*, Shalini, Kumari Sadhana, Rahman Ur Mujeeb \\ Alwar Pharmacy College, North Extension, MIA, Alwar, Rajasthan.301030
}

\begin{abstract}
In past there have been many medicinal plants, which have been used in traditional medicines for their antihyperglycemic properties without any scientific support and pharmacological evidence. The aqueous extract of Withania coagulans dunal fruit has been taken to evaluate the antihyperglycemic activity in normal and streptozotocin-induced diabetic rats. The plant is known as 'the cheese maker' or 'vegetable rennet' because fruits and leaves of the plant are used as a coagulant. The milk coagulating property of the fruit is attributed to the pulp and husk berries which posses an enzyme which has milk coagulating activity an antihyperglycemic activity of aqueous extract has not been yet done, as no such reports are available in the literature through the activity is reported. The scientific evaluation of its antihyperglycemic activity was, therefore, explored and also compared with the effect of a standard hypoglycemic drug, glibenclamide. A single oral administration of variable dose levels $(100,200$ and $300 \mathrm{mg} / \mathrm{kg} \mathrm{b} . \mathrm{wt}) \mathrm{of}$ aqueous extract led to lowering of blood glucose level in normal as well as in diabetic rats. In acute treatment maximum \% reduction in glucose level $(57.02 \%)$ was seen with $300 \mathrm{mg} / \mathrm{kg}$ b. wt WCD at $6 \mathrm{hr}$ while with standard drug maximum $\%$ reduction $(62.25 \%)$ at 6 hr was found. In subacute study the maximum \% reduction in blood glucose level was found (57.22\%) with WCD aq. extract in dose $300 \mathrm{mg} / \mathrm{kg} \mathrm{b}$. wt which is slightly lesser then the \% reduction seen with standard drug (64.52\%) respectively. Both the doses $100 \&$ $200 \mathrm{mg} / \mathrm{kg} \mathrm{b}$. wt of WCD showed significant effect $(\mathrm{p}<.05)$ at $4 \mathrm{hr}$ and highly significant $(\mathrm{p}<0.01)$ at $6 \mathrm{hr}$ while in chronic treatment both the doses showed significant reduction in blood glucose from $14^{\text {th }}$ day to $28^{\text {th }}$ days. The findings from this study suggest that the aqueous extract of these fruits may be prescribed as adjunct to dietary therapy and drug treatment for controlling diabetes mellitus.
\end{abstract}

Keywords: Withania coagulans, Antihyperglycemic activity, Diabetes mellitus; Streptozotocin

Article Info: Received 16 Jan, 2018; Review Completed 5 March, 2018; Accepted 7 March, 2018; Available online 15 March, 2018

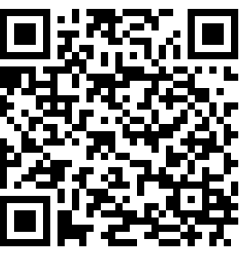

Cite this article as:

Upadhayay As, Shalini, Kumari S, Rahman UM, Evaluation of antidiabetic activity of fruits of Withahnia coagulans in streptozocin induced diabetic rats, Journal of Drug Delivery and Therapeutics. 2018; 8(2):25-28

DOI: http://dx.doi.org/10.22270/jddt.v8i2.1678

*Address for Correspondence

Dr. Ashutosh Upadhayay, Professor \& HOD, Department of Pharmacology, Alwar Pharmacy College, North Extension, MIA, Alwar, Rajasthan.301030, Mobile No: 9887769310

\section{INTRODUCTION}

Diabetes currently is a major health problem for the people of the world. Diabetes is a chronic disorder of carbohydrate, fat and protein metabolism characterised by elevation of both fasting and post-paradinal blood sugar levels. The synthetic oral hypoglycemic agents can produce serious side effects. In addition, they are not considered to be safe for use during pregnancy. Furthermore, after the recommendation made by WHO on diabetes mellitus investigation on hypoglycemic agents from medicinal plants have become more important $^{1-4}$.
W. coagulans (family: Solanaceae) is commonly known as 'Panir ke phool' in Hindi and is widely and regularly used in India and other tropical countries. W. coagulans dunal is very well known for its ethno pharmacological activities. In Punjab, the fruits of $W$. coagulans are used as the source of coagulating enzyme for clotting the milk which is called 'paneer'. Buffalo or sheep milk is warmed to about $100{ }^{\circ} \mathrm{F}$ and crushed berries of plant, tied in cloth, are dipped in it. The milk takes 30-40 minutes to curdle. The plant is known as 'the cheese maker' or 'vegetable rennet' because fruits and leaves of the plant are used as a coagulant. The milk coagulating 
property of the fruit is attributed to the pulp and husk berries which posses an enzyme which has milk coagulating activity. W. coagulans is used in chronic complaints of liver. A composite Ayurvedic herbal hepatoprotective medicine 'Liv-52' contains extracts of $W$. coagulans and $W$. somnifera. They are also used in diabetes, dyspepsia, flatulent colic and other intestinal infections. In some parts of Pak-Indian sub-continent, the berries are used as a blood purifier. The twigs are chewed for cleaning of teeth and the smoke of the plant is inhaled for relief in toothache $e^{5-8}$.

The present study was undertaken to study the antihyperglycemic effect of aqueous extract of the fruits of $W$. coagulans in normal and streptozotocin induced diabetic rats.

\section{MATERIAL AND METHOD}

\subsection{Plant material}

Fresh fruits of $W$. coagulans $(3 \mathrm{~kg})$ were collected locally and got identified by Botanical survey of India, Jodhpur. The leaves were shade dried and were crushed to moderately coarse powder.

\subsection{Preparation of extract}

The powder was extracted with distilled water using soxhelt at boiling temperature $\left(105^{\circ} \mathrm{C}\right)$ up to $9 \mathrm{~h}$. A dark brown colour extract is obtained. This dark brown extract was cooled and filtered to remove the residue. The extract was concentrated on rotavapour under reduced pressure and then lyophilized to get a powder weighing about $4 \mathrm{~g}^{9,10,11}$.

\subsection{Experimental animals}

Male Albino wister rats weighing between 130 and 180 $\mathrm{g}$ were used and were maintained on commercial diet and water ad libitum. They were acclimated to the laboratory conditions before carrying out any experimental work. Studies were carried out after the approval of Institutional Animal Ethical Committee in accordance with institutional ethical guidelines for the care of laboratory animals of Alwar Pharmacy College, Alwar, Raj, India (approval no.- APC/IEAC/2017/RP003).

Diabetes mellitus was induced by administering intraperitonial injection of streptozotocin $(45 \mathrm{mg} / \mathrm{kg}$ b.wt, Sigma chemicals, USA) dissolved in citrate buffer (pH 4.00) to the overnight fasted rats. Fasting blood glucose (FBG) level was checked regularly up to stable hyperglycemia after 7days of strpetozotocin administration. The blood glucose level (BGL) was determined by glucose oxidase method. The rats were divided in to different groups. The rats having FBG value greater than $250 \mathrm{mg} / \mathrm{dl}$ were considered. Rats that did not show any increase in FBG levels even initially after streptozotocin injection were considered as totally resistant and were excluded from studies. Antihyperglycemic activity was assessed by lowering of $\mathrm{BGL}$ in normal and diabetic rats ${ }^{12-15}$.

\subsection{Experimental design}

The experimental diabetes was induced in albino wistar rats by intra-peritoneal administration of streptozotocin. The rats were divided into six groups after the induction of diabetes. In the experiment 6 rats were uses in each group. Aqueous extract of $W$. coagulans dunal fruits was given with the help of oral feeding tube to streptozotocin induce diabetic rats.

\subsection{Effect of W. coagulans extract on blood glucose level of rats (Acute Study and Sub Acute Study)}

In overnight, fasted rats FBG was checked and then they were divided into six groups of six rats each. Group I served as control and received vehicle $(2 \mathrm{ml}$ of normal saline) only. Group II served as diabetic control and received vehicle ( $2 \mathrm{ml}$ of normal saline ), Groups III received standard drug glibenclamide and IV, V and VI were given aqueous fruits extract suspended in distilled water orally at doses 100,200 and $300 \mathrm{mg} / \mathrm{kg}$ body weight, respectively. Blood samples were collected from the tail vein. 2, 4 and $6 \mathrm{~h}$ after giving the extract for acute study as well as blood samples were collected from the tail vein. 7, 14, 21 and 28 days after giving the extract for subacute study.

\subsection{Statstical analysis}

The entire group data were statistically evaluated using student's $t$-test, expressed as the mean \pm S.D. from six rats in each group. $P$-value of 0.05 or less was considered to be significant.

\section{RESULTS}

Graph-1 and 2 shows the blood glucose levels of diabetic control, WCD aq. extract and glibenclamide treated rats. In diabetic control rats, the increase in blood glucose concentration was observed after $2 \mathrm{hr}$ and remained high throughout the study. Aq. extract of WCD (300 mg/kg b.wt.) and glibenclamide $(600 \mu \mathrm{g} / \mathrm{kg}$ body wt.) treated rats showed significant decrease in blood glucose concentration when compared with diabetic control rats.

Result obtained from WCD aq. extract indicate that WCD aq. extract at $300 \mathrm{mg} / \mathrm{kg}$ b.wt showed more significant $(p<0.01)$ antidiabetic activity in acute as well as in chronic treatment when compared with diabetic control group. In acute treatment maximum \% reduction in glucose level $(57.02 \%)$ was seen with $300 \mathrm{mg} / \mathrm{kg}$ b.wt WCD at $6 \mathrm{hr}$ while with standard drug maximum \% reduction $(60.71 \%)$ at $6 \mathrm{hr}$ was found. In chronic treatment the maximum $\%$ reduction in blood glucose level was found $(59.44 \%)$ with WCD aq. Extract in dose $300 \mathrm{mg} / \mathrm{kg}$ b.wt which is slightly lesser then the \% reduction seen with standard drug (64.23\%) respectively. Both the doses $100 \& 200 \mathrm{mg} / \mathrm{kg} \mathrm{b}$.wt of WCD showed significant effect $(\mathrm{p}<.05)$ at $4 \mathrm{hr}$ and highly significant $(\mathrm{p}<0.01)$ at $6 \mathrm{hr}$ while in chronic treatment both the doses showed significant reduction in blood glucose from $14^{\text {th }}$ day to $28^{\text {th }}$ days. The antidiabetic studies of WCD aq. extract on streptozotocin induced diabetic rats showed that WCD posses highly significant antidiabetic effect with minimal toxicity at $300 \mathrm{mg} / \mathrm{kg} \mathrm{b}$.wt body weight as well as $200 \mathrm{mg} / \mathrm{kg}$ b.wt body weight and least activity at 100 $\mathrm{mg} / \mathrm{kg}$ b.wt body weight. 
Table 1: Influence in blood glucose level of diabetic rat after treat them with Withania coagulans dunal aqueous extract and standard antidiabetic drug (0 hour, 1 hour, 3 hour, 5 hour and 7 hour)

\begin{tabular}{|c|c|c|c|c|c|}
\hline \multirow{2}{*}{ Group (n) } & \multicolumn{5}{|c|}{ Blood glucose level (mg/dl) } \\
\cline { 2 - 6 } & $\mathbf{0}$ hour & $\mathbf{2}$ hour & $\mathbf{4}$ hour & $\mathbf{8}$ hour & $\mathbf{2 4}$ hour \\
\hline NC & $96 \pm 0.76$ & $98 \pm 0.74$ & $100 \pm 1.22$ & $102 \pm 1.68$ & $101 \pm 1.34$ \\
\hline DC & $270 \pm 1.96$ & $285 \pm 2.44$ & $278 \pm 2.36$ & $272 \pm 3.25$ & $271 \pm 3.16$ \\
\hline WCD-300 & $276 \pm 5.26$ & $221 \pm 5.27$ & $208 \pm 4.51$ & $196 \pm 4.49$ & $188 \pm 4.02$ \\
\hline WCD-200 & $272 \pm 4.22$ & $231 \pm 6.77$ & $218 \pm 6.18$ & $209 \pm 3.34$ & $203 \pm 3.03$ \\
\hline WCD-100 & $280 \pm 5.26$ & $242 \pm 6.80$ & $233 \pm 5.81$ & $224 \pm 6.38$ & $222 \pm 6.41$ \\
\hline GLB-600 & $271 \pm 4.4$ & $218 \pm 6.21$ & $210 \pm 5.64$ & $202 \pm 5.71$ & $229 \pm 5.5$ \\
\hline
\end{tabular}

Table 2: Influence in blood glucose level of diabetic rat after treat them with Withania coagulans dunal aqueous extract and standard antidiabetic drug (0 day, 7, 14, 21 \& 28 day)

\begin{tabular}{|c|c|c|c|c|c|}
\hline \multirow{2}{*}{ Group (n) } & \multicolumn{5}{|c|}{ Blood glucose level (mg/dl) } \\
\cline { 2 - 6 } & $\mathbf{4}^{\text {th }}$ day & $\mathbf{7}^{\text {th }}$ day & $\mathbf{1 4}^{\text {th }}$ day & $\mathbf{2 1}^{\text {st }}$ day & $\mathbf{2 8}^{\text {th }}$ day \\
\hline NC & $104 \pm 1.03$ & $103 \pm 1.76$ & $104 \pm 1.94$ & $102 \pm 1.86$ & $101 \pm 1.54$ \\
\hline DC & $290 \pm 3.18$ & $294 \pm 3.94$ & $295 \pm 3.79$ & $298 \pm 2.5$ & $295 \pm 3.22$ \\
\hline W.C.D-300 & $183 \pm 3.83$ & $173 \pm 3.34$ & $161 \pm 3.82$ & $149 \pm 3.54$ & $131 \pm 4.62$ \\
\hline WCD-200 & $204 \pm 3.39$ & $201 \pm 3.12$ & $194 \pm 3.54$ & $184 \pm 4.26$ & $173 \pm 4.26$ \\
\hline WCD-100 & $224 \pm 6.12$ & $220 \pm 5.38$ & $214 \pm 5.34$ & $202 \pm 5.99$ & $192 \pm 4.84$ \\
\hline GLB-600 & $206 \pm 4.16$ & $163 \pm 4.02$ & $141 \pm 2.85$ & $122 \pm 2.13$ & $109 \pm 2.88$ \\
\hline
\end{tabular}

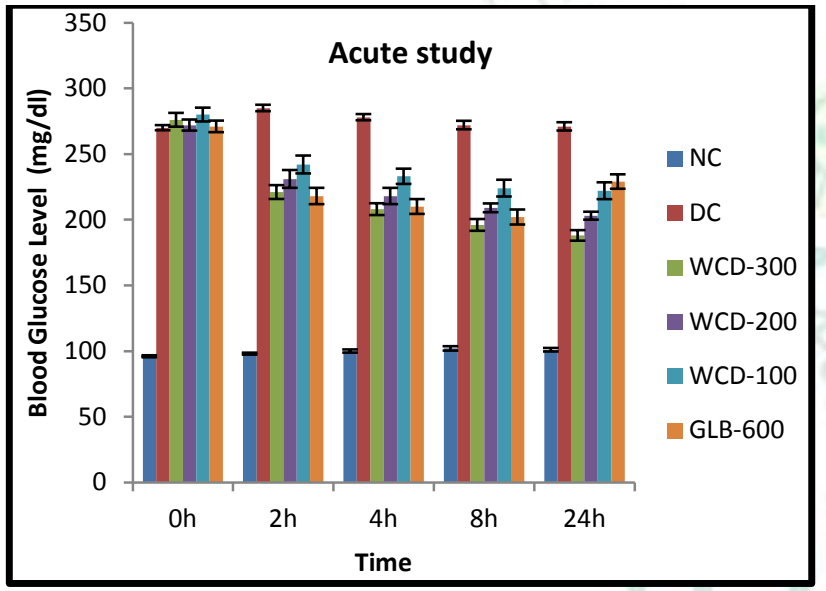

Graph- 1 Effect of different extract of W. coagulans on blood glucose level in streptozotocin induced diabetic rats for acute study

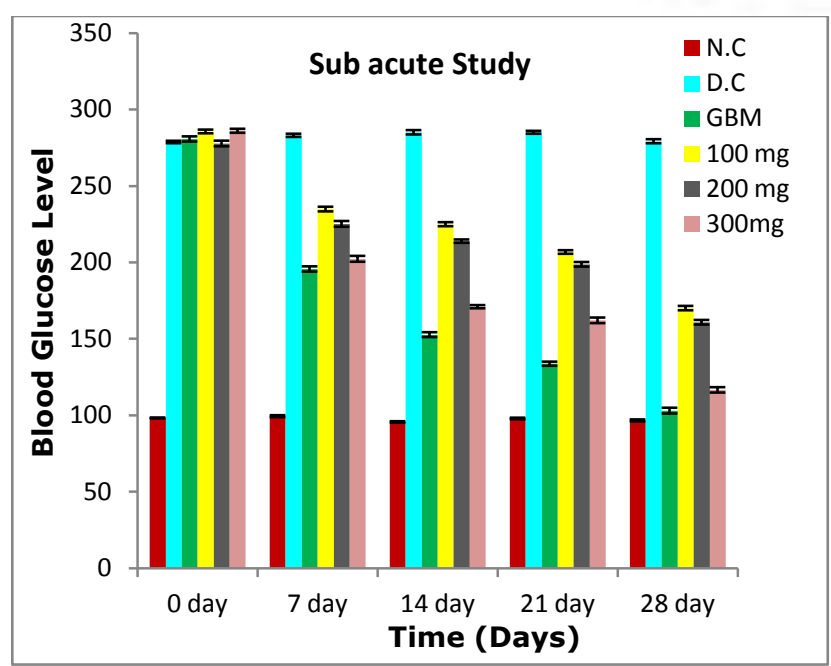

Graph-2 Effect of different extract of W. coagulans on blood glucose level in streptozotocin induced diabetic rats for subacute study.

\section{DISCUSSION}

Streptozotocin causes massive reduction in insulin release, through the destruction of beta cells of islets of langerhens. In our study, we have observed a significant antidiabetic action of WCD aq. extract at 300 and 200 $\mathrm{mg} / \mathrm{kg}$ b.wt. This could be due to potentiation of the insulin effect of plasma by increasing the pancreatic secretion of insulin from existing beta cells of islets of langerhens or its release from bound insulin. The significant and consistent antidiabetic effect of WCD aq. extract in streptozotocin induce diabetic rats may also be due to enhanced glucose utilization by peripheral tissues. SGPT \& SGOT are liver function test that give information about patients liver. Liver transaminase is useful biomarker of liver injury in a patient with a degree of intact liver function. Due to poor blood glucose control fat can deposited in liver, which may lead to rise in SGPT/SGOT.

Hemoglobin HbA1c test also called HbA1c, Glycated hemoglobin test or glycohemoglobin is an important blood test that shows how diabetes is being controlled. HbAlc provides an average of blood sugar control over the past 2 to 3 months. Hemoglobin is found in RBC, which carry oxygen throughout body. When diabetes is not controlled then sugar build up in blood and combine with hemoglobin become Glycated.

The conclusions derived from results revealed a defined role of the aqueous extract of $W$. coagulans fruits in suppressing blood glucose level in normal and diabetic rats. The aqueous extract in all the three doses produced significant hypoglycemic effect after $4 \mathrm{~h}$ administration. It is also clear that the hypoglycemic effect of variable dose of extract had begun 2 hours and was maximum at 6 hours in all the groups. As far as most effective dose is concern it has been found to be $300 \mathrm{mg} / \mathrm{kg}$ b.wt in all the groups. This dose has almost same effect as of synthetic 
drug glibenclamide. Further comprehensive pharmacological investigation is in progress to elucidate the exact mechanism of action of this extract.

\section{Acknowledgements}

The authors wish to thank Dr. G Jeyabalan, Principal,
Alwar College of Pharmacy, Alwar, for supervising throughout the period of this research work. I would also like to give special thanks to Mr. Gaurav soni and Mr. Nitin Jumnani for his inspiration \& providing necessary facilities to carry out this research work.

\section{REFERENCES}

1. Datta A et al, "Antidiabetic and antihyperlipidemic activity of hydroalcoholic extract of Withania coagulans Dunal dried fruit in experimental rat models". PMC article, 2013; 4(2):99106.

2. Banshidhar B, Deepmala Y, "Current Researches on Plants Having Antidiabetic Potential". Research and Reviews: Journal of Botanical Sciences, 2013; 2(2):4-17.

3. HG. Vogel et al, "Drug discovery and Evaluation". Pharmacological Assays, Second Edition; 2002: 948.

4. Tripathy KD, "Essentials of pharmacology". $4^{\text {th }}$ edition, New Delhi, Jaypee brother's medical publishers Pvt. Ltd. '1999: 256.

5. Larner, J., 1985. Insulin and oral hypoglycemic drugs; Glucagon. In: Gilman, A.G., Goodman, L.S., Rall, T.W., Murad, F. (Eds.), The Phar- macolgical Bases for Therapeutic, seventh ed. Macmillan, New York, pp. 149-151.

6. Imran M, Khan M, Akhtar R, Ahmed S, Rageeb M. Antidiabetic and hypolipidemic effect of methanol extract of stereospermum colais fruit in streptozotocin induced diabetic rats. Journal of Drug Delivery and Therapeutics, 2016; 6(4):41-47. doi:10.22270/jddt.v6i4.1272

7. Jhansee M, Alok DK, Shailesh MN, Ashish GK, "Withania Coagulans in Treatment of Diabetics and Some Other Diseases: A Review". Research Journal of Pharmaceutical, Biological and Chemical Sciences, April-June 2013; 4(2): 1251 .

8. Manivannan R, Shopna R, Antidiabetic activity of Calotropis gigantea white flower extracts in alloxan induced diabetic rats. Journal of Drug Delivery and Therapeutics, 2017;
7(3):106-111. doi:10.22270/jddt.v7i3.1447

9. Akhtar MS, Iqbal J. Evaluation of the hypoglycemic effect of Achyranthes aspera in normal and streptozotocin diabetic rats. Journal of Ethnopharmacology 1991; 31:49-57.

10. Imran M, Khan M, Akhtar R, Ahmed S, Rageeb M, Antidiabetic and hypolipidemic effect of methanol extract of Stereospermum colais fruit in streptozotocin induced diabetic rats. Journal of Drug Delivery and Therapeutics, 2016; 6(4):41-47. doi:10.22270/jddt.v6i4.1272.

11. Malviya S, Vyas N, Joshi A, Kharia A, Malviya N, Pharmacological Assessment of Antidiabetic Potential of Hydroalcoholic Extract of Cassia fistula Linn. in Streptozotocin-induced Diabetic Rats. Journal of Drug Delivery and Therapeutics, 2017; 7(7):168-169. doi:10.22270/jddt.v7i7.1623.

12. Chetan S, Amrinder S, Anuj M, Prabhsimran S, "Investigation of the Pharmacognostical, Phytochemical and Antioxidant Studies of Plant Withania coagulans Dunal", Journal of Pharmacognosy and Phytochemistry. 2012; 1:32-39.

13. Sharma SR, Dwivedi SK, Swarup D, Hypoglycaemic and hypolipidemic effects of Cinnamomum tamala Nees leaves. Indian Journal of Experimental Biology 1996; 34:372-374.

14. Szkudelski T, "The mechanism of Alloxan and Streptozotocin action in $\beta$-cells of the pancreas". Physiol Res 2001; 50:53646.

15. Li WI, Zheng HC, Bukuru J, De Kimpe N, "Natural medicines used in the traditional chinesemedical system for the therapy of diabetes mellitus", Journal of Ethan pharmacology. 2004; 92:1-21. 